\title{
INFILTRATION-EXFILTRATION SYSTEM FOR STORMWATER RUNOFF VOLUME AND PEAK ATTENUATION
}

\author{
MARIANA MARCHIONI \& GIANFRANCO BECCIU \\ Politecnico di Milano
}

\begin{abstract}
Urbanization alters the hydrological cycle increasing surface runoff water volume and peak flow. The traditional approach on urban drainage is being updated to an integrated approach of managing the water on its source. This study proposes a strategy based on urban retrofit of impervious surfaces using an infiltration-exfiltration linear system of runoff collection. The proposed system is based on street side channels and is composed by a porous asphalt top layer, aggregates base and drainage underdrain. The aims are to promote infiltration, filtration and adsorption of stormwater. Storm water management model was used to simulated pre and post-retrofit response for extreme single events on the city of Milan from 2006 to 2015. The system has positive effects on runoff reduction and hydrograph attenuation reaching from $18 \%$ reduction to full infiltration of runoff volume.
\end{abstract}

Keywords: stormwater, SUDs, sustainable drainage, floods

\section{INTRODUCTION}

Traditional urban road drainage consists on directing runoff water to the kerbs, collecting on catch pits placed on suitable intervals across the roads that proceeds to the sewers system [1]. The saturation of the sewer system often occurs on high intensity events creating the necessity of storage tanks across the drainage system [2]. However, this traditional solution has become impractical on current urbanization scenarios pushing towards comprehensive measures such as promoting stormwater management on its source $[2,3]$. These measurements are commonly known as SUDs (sustainable urban drainage systems), BMPs (best management practices) or LIDs (low impact developments) and have a different approach of solutions to achieve a long term and sustainable urban drainage management [4]. This study proposes a solution based on the integration of porous pavement and traditional drainage system. An infiltration-exfiltration system is placed along the road replacing the traditional gutters, composed by a porous asphalt top layer and aggregate base, allowing infiltration to the underground soil. This solution promotes attenuation on extreme rainfall events, aquifer recharge and water quality improvement. The objective of this preliminary study is to evaluate the linear infiltration-exfiltration system performance in terms of runoff volume reduction and peak attenuation.

\section{BACKGROUND}

The city of Milan suffers with increasing frequency from floods, especially on the North area - in the last 140 years 342 floods were registered (i.e. 2.4 per year), 108 of which from 1976 only (i.e. 2.6 per year). The river Seveso, that crosses the city, often causes flooding and a solution using storage tanks would have a cost estimated on 130 million Euros [2]. The 1937 $\mathrm{km}$ of roads provide significant contribution to surface runoff water and management this water volume locally could alleviate the sewer system saturation. On [5] a prototype infiltration-exfiltration device was constructed on the side of a pavement section of a urban road on Cincinnati, United States, obtaining positive impacts on flow reduction and load removal. 
The system was also model using a 2D numerical unsaturated flow model (VS2DT) to evaluate different soil types and rainfall events concluding that on the study conditions the peak flow and total flow decreased even with different type of soil on the surroundings of the system

The Storm Water Management Model (SWMM) from EPA-US (United States Environmental Protection Agency) is often used to model the rainfall-runoff transformation processes and the hydrograph estimation in both pre and post-retrofit scenarios [6-11]. SWMM provides dynamic rainfall-runoff simulation for both single event and long term (continuous) simulation of runoff quantity and quality specially on urban areas. The model provide from EPA-US operates on a collection of subcatchment areas that receive precipitation and generate runoff and pollutant loads [12]. The model has an in-build option to model LIDs including infiltration devices and permeable pavement. Although often used, the LID block of SWMM may overestimate the results on volume and peak flow [13]. A robust model will depend highly of the parameters estimation, whereas area and imperviousness have the most significant impact on the hydrograph [12].

\section{METHODOLOGY}

The city of Milan is circled by two road rings, the inner one with $11.2 \mathrm{~km}$ surrounding the historical old city centre and the outer one, with $19.5 \mathrm{~km}$, surrounding most of the XX century quarters. The linear infiltration-exfiltration system was tested on a potential application along both rings to evaluate the impact of road retrofitting at catchment level.

The potential benefits of installing the proposed infiltration-exfiltration system on both roads were analysed through simulation of effects on stormwater runoff infiltrated and diverted from the sewer system.

\subsection{Simulations}

Table 1 shows the subcatchment parameters used on the simulations. The considered area regards a stretch of road served by one inlet, the width represents the flow path, $\mathrm{N}$ represents

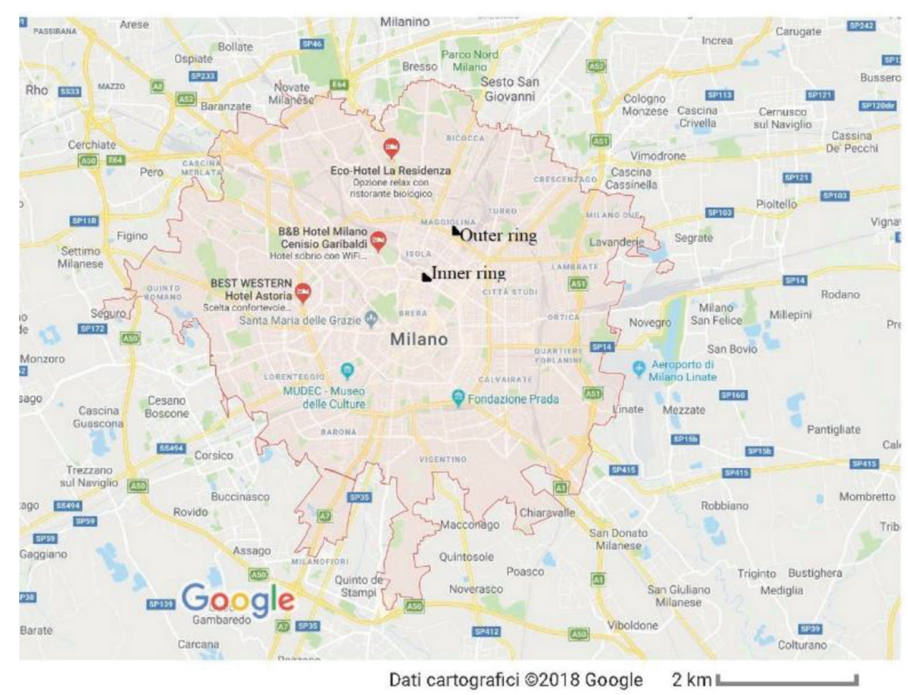

Figure 1: Inner and outer ring road of Milan. 
Table 1: Parameters used on the rainfall-runoff simulation

\begin{tabular}{ll} 
Parameter & \\
\hline area (ha) & 0.008 \\
width (m) & 8 \\
\% slope & 2 \\
N-imperv & 0.017 \\
N-perv & 01 \\
D-store-imperv (mm) & 1.1 \\
D-store-perv (mm) & 5
\end{tabular}

the roughness considering the Manning's number, D-storage represents depression storage. The parameters where estimated considering the half road area, typical urban road slope, typical $\mathrm{N}$ and $\mathrm{D}$-Storage for old asphalt. The model was calibrated using runoff data from a similar road for the city of Cincinnati, United States [14]. The linear infiltration-exfiltration system was model as a LID system using the in-build function on SWMM.

\subsection{Design storm}

The rainfall data was recorded in the Lambrate Station on the city of Milan, Italy, between 2006 and 2015. A IETD (minimum interevent time) of 1 hour was considered to define independent events [15]. Table 2 presents main statistics of this series yearly and Table 3 for the complete period. Simulations were then performed for ten extreme single events, extracted from the series (Table 4). The highest event record was registered on 2009 with a $121.2 \mathrm{~mm}$ rain depth and maximum intensity of $176.4 \mathrm{~mm} / \mathrm{h}$.

\subsection{Linear infiltration-exfiltration system}

The linear infiltration-exfiltration system consists of a porous asphalt surface layer, an underlying gravel layer and receives the sheet flow from the corresponding strip of street. The

Table 2: Rainfall events recorded in each year of the series.

\begin{tabular}{llllll}
\hline Year & $\mathrm{T}_{\mathrm{r}}$ & $\theta[$ hours $]$ & $\mathrm{H}_{\text {tot }}[\mathrm{mm}]$ & $\mathrm{t}_{\mathrm{sr}}[$ days $]$ & $\mathrm{i}_{\max }[\mathrm{mm} / \mathrm{h}]$ \\
\hline 2006 & 80 & 9 & 730 & 49 & 156 \\
2007 & 55 & 4.5 & 388.8 & 111 & 26.4 \\
2008 & 113 & 5 & 1245.40 & 42 & 136.8 \\
2009 & 109 & 9 & 1112 & 25 & 176.4 \\
2010 & 135 & 6.5 & 1467.2 & 23 & 68.4 \\
2011 & 64 & 4.5 & 548.8 & 35 & 69.6 \\
2012 & 93 & 7 & 1061 & 58 & 106.8 \\
2013 & 120 & 9 & 1249.6 & 33 & 112.8 \\
2014 & 163 & 12 & 1639 & 28 & 81.6 \\
2015 & 85 & 5.5 & 778.4 & 32 & 84 \\
\hline
\end{tabular}

$\mathrm{T}_{\mathrm{r}}$ : total rainfall events, $\theta$ : maximum rainfall duration, $\mathrm{h}_{\text {tot }}:$ yearly total rainfall, $\mathrm{t}_{\mathrm{sr}}$ : maximum dry period, $\mathrm{i}_{\text {max }}$ : maximum rainfall intensity. 
Table 3: Average rainfall statistics in the recorded rainfall series.

\begin{tabular}{ll}
\hline & Milan-Lambrate \\
\hline Number of years & 10 \\
Total number of events & 1017 \\
Average number of events per year $\left(\mathrm{E}_{\mathrm{v}}\right)$ & 101.7 \\
$\mathrm{E}_{\mathrm{v}}$ standard deviation & 31.3 \\
Average yearly rainfall $\left(\mathrm{h}_{\text {tot }}\right)[\mathrm{mm}]$ & 1022.0 \\
$\mathrm{~h}_{\text {tot }}$ standard deviation & 382.1 \\
Average number of dry days $\left(\mathrm{t}_{\mathrm{sr}}\right)$ & 43.6 \\
Maximum number of dry days & 111 \\
$\mathrm{t}_{\text {sr }}$ standard deviation & 24.7 \\
Average peak flow intensity $\left(\mathrm{i}_{\max }\right)[\mathrm{mm} / \mathrm{h}]$ & 101.9 \\
$\mathrm{i}_{\text {max }}$ standard deviation & 42.9 \\
Average rainfall duration $(\theta)[$ hours $]$ & 7.2 \\
$\theta$ standard deviation & 2.4 \\
\hline
\end{tabular}

Table 4: Characteristics of extreme rainfall events used for simulations.

\begin{tabular}{lllll}
\hline Event Measured & $\begin{array}{l}\text { Rainfall } \\
\text { duration }(\mathrm{min})\end{array}$ & Rain depth $(\mathrm{mm})$ & $\mathrm{i}_{\max }(\mathrm{mm} / \mathrm{h})$ & $\mathrm{i}_{\text {avr }}(\mathrm{mm} / \mathrm{h})$ \\
\hline $06 / 07 / 2006$ & 240 & 44 & 156 & 10.56 \\
$04 / 07 / 2007$ & 90 & 5.6 & 26.4 & 3.4 \\
$12 / 07 / 2008$ & 30 & 27.4 & 136.8 & 82.2 \\
$07 / 07 / 2009$ & 260 & 121.2 & 176.4 & 26.93 \\
$11 / 07 / 2010$ & 180 & 24.6 & 68.4 & 7.8 \\
$27 / 05 / 2011$ & 240 & 37.8 & 69.6 & 8.4 \\
$09 / 06 / 2012$ & 110 & 38 & 106.8 & 19 \\
$24 / 08 / 2013$ & 190 & 26.8 & 112.8 & 8.0 \\
$24 / 06 / 2014$ & 60 & 37.2 & 81.6 & 31.9 \\
$25 / 07 / 2015$ & 90 & 34.6 & 55.2 & 20.7 \\
\hline
\end{tabular}

system was designed in an analogue way as a detention basin. Due to the short water paths, the system balance was simulated neglecting the rainfall-runoff transformation on the street [1].

$$
\begin{gathered}
\theta_{w}=\left(\frac{Q_{u}}{2,78 \cdot A \cdot \varphi \cdot a \cdot n}\right)^{\frac{1}{n-1}} \cdot \\
W_{o}=10 . \text { A. } \text {. a. } \theta_{w}^{n}-3.6 \cdot Q_{u \max } \cdot \theta_{w}
\end{gathered}
$$

where $\theta \mathrm{w}$ is the critical rainfall duration, $\mathrm{Q}_{\mathrm{u}}$ is the outflow discharge, $\mathrm{A}$ is the area, $\varphi$ is the permeability coefficient, "a" and " $n$ " are the 2-parameters IDF curves coefficients for Milano [16]. A limit of $20 \mathrm{l} / \mathrm{s} / \mathrm{ha}$ was considered for discharges in the sewer network, as provided by local regulations. The possibility of system storage pre-filling from previous events wasn't considered $[17,18]$. 


\section{RESULTS}

4.1 near infiltration-exfiltration system cross section

The linear infiltration and exfiltration system cross section designed accordingly to above methodology is presented in Fig. 2. To guarantee the limit outflow the underdrain should be placed on a higher position and an eventual flow restriction device should be considered.

\subsection{Pre and post retrofit hydrographs}

Figure 3 shows the pre and post-retrofit scenarios hydrograph, where the retrofit consists in considering the linear infiltration-exfiltration system replacing the street gutters. Except for the year 2009 the system was able to infiltrate most of the single extreme events, reaching full infiltration for the 2007 event. In all events there was a considerable reduction of peak flow.

Table 5 shows the total runoff volume pre and post retrofit for the considered roach stretch with an average of $60 \%$ reduction. The 2007 event was fully infiltrated by the device while the 2009 present a $18 \%$ reduction on volume

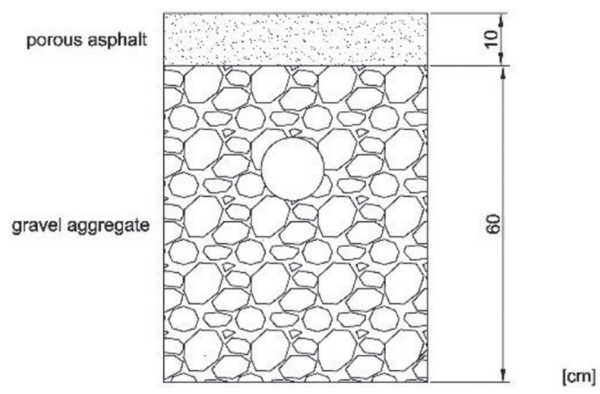

Figure 2: Linear infiltration and exfiltration system. Units in $\mathrm{cm}$.

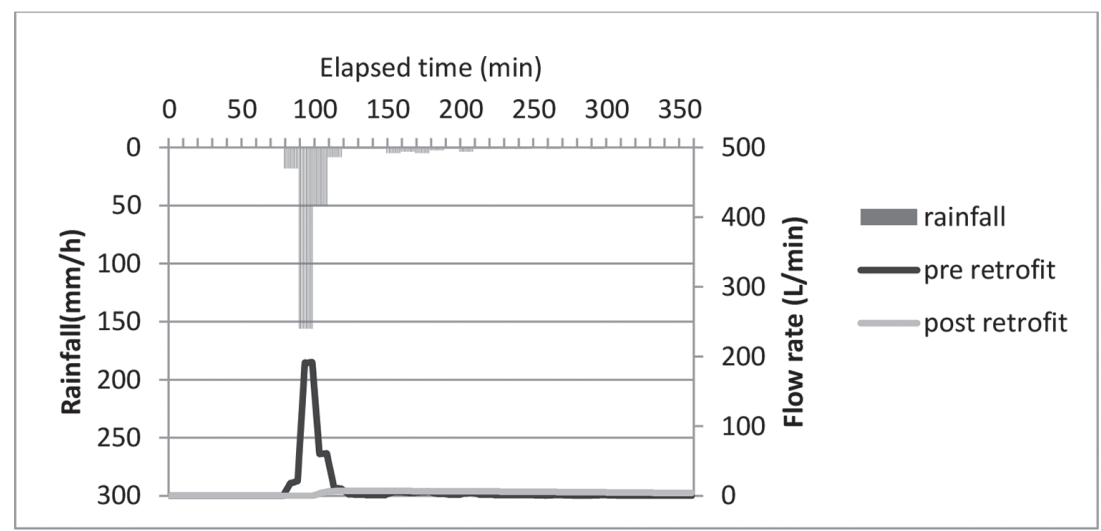

(a)

Figure 3: Pre and post retrofit hydrographs for extreme rainfall single events. (a) 2006; (b) 2007; (c) 2008; (d) 2009; (e) 2010; (f) 2011; (g) 2012; (h) 2013; (i) 2014; (j) 2015. 


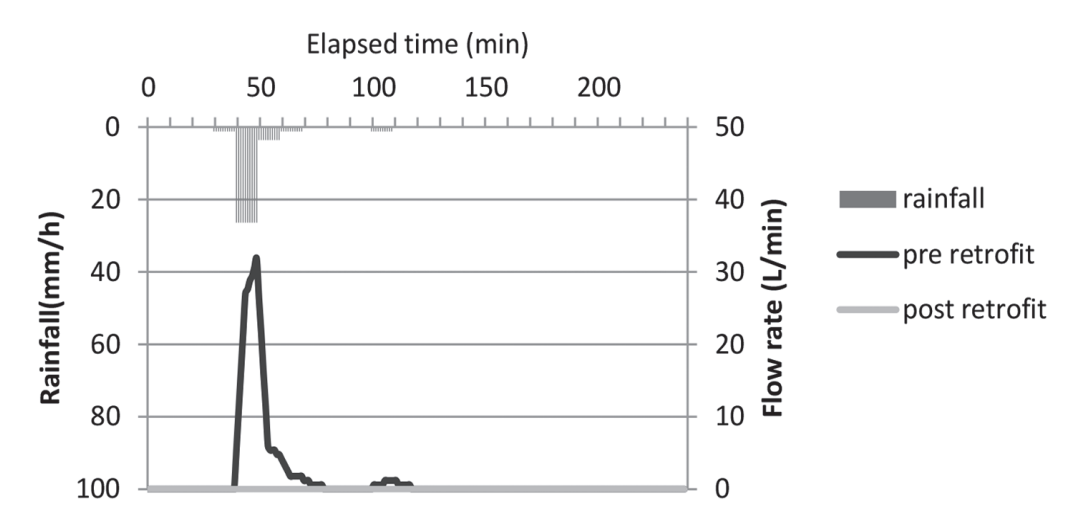

(b)

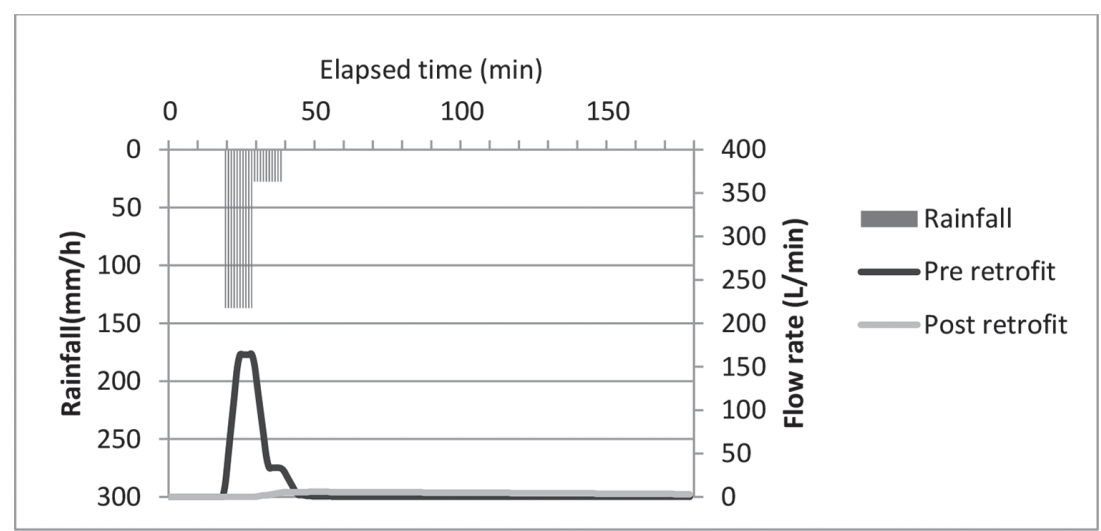

(c)

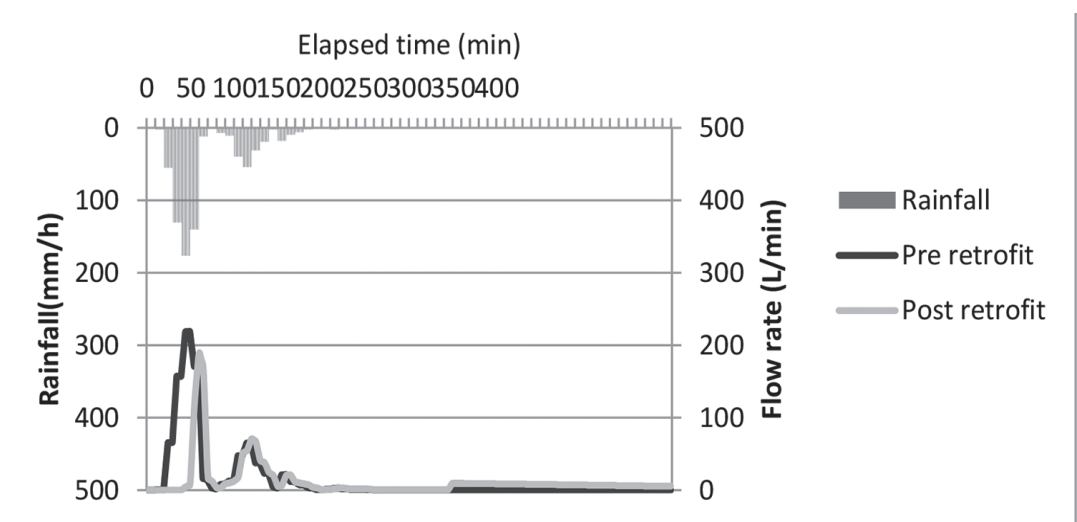

(d)

Figure 3: (Continued) 


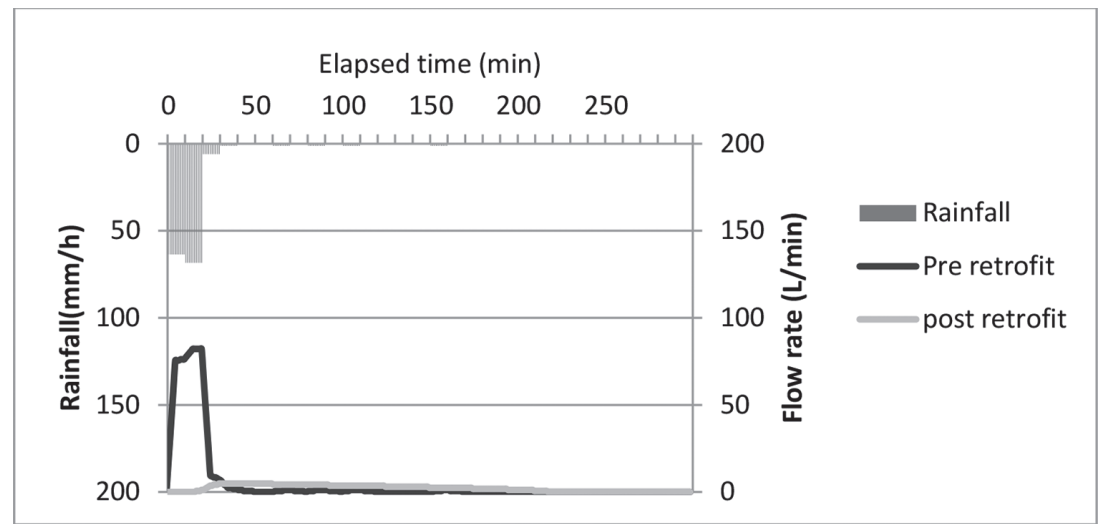

(e)

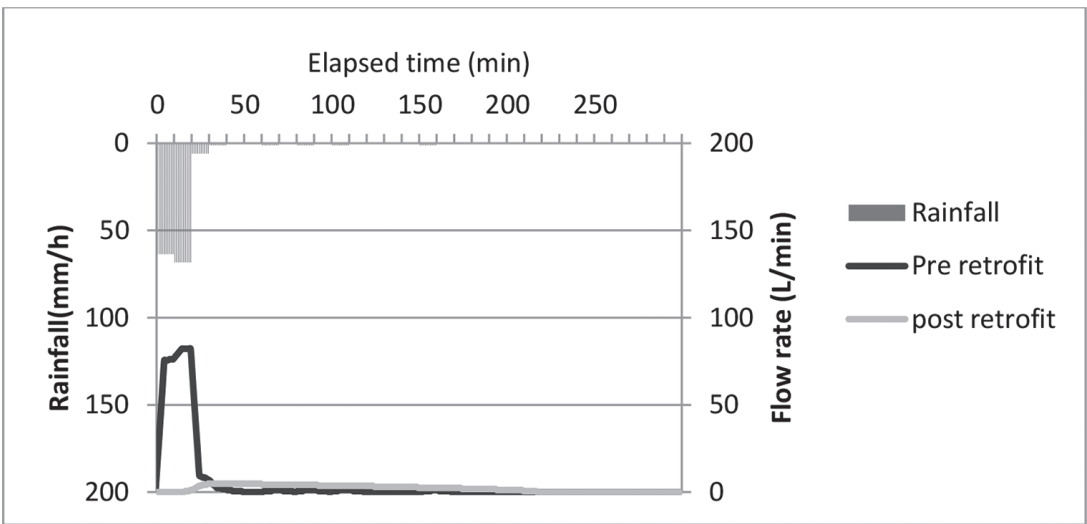

(f)

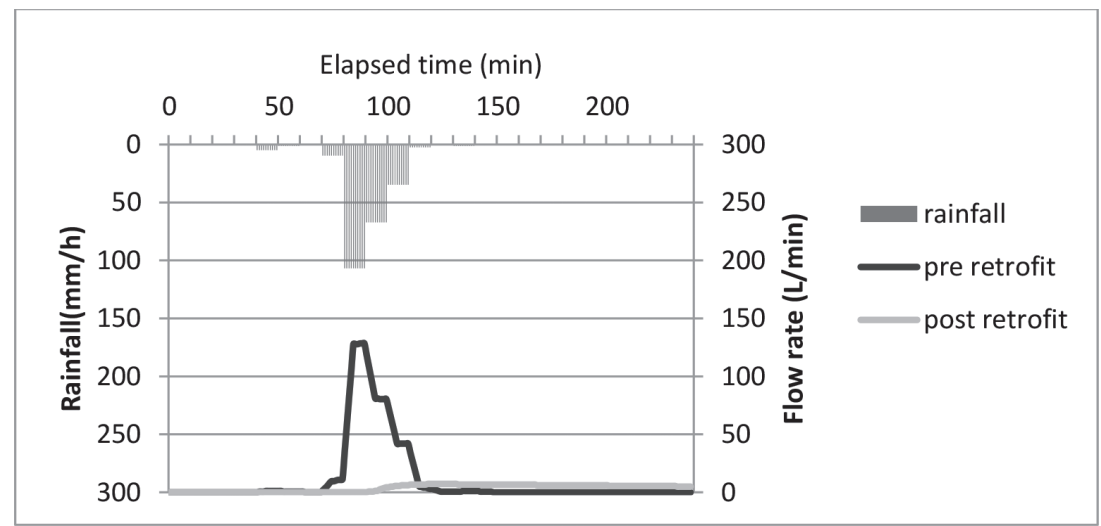

(g)

Figure 3: (Continued) 


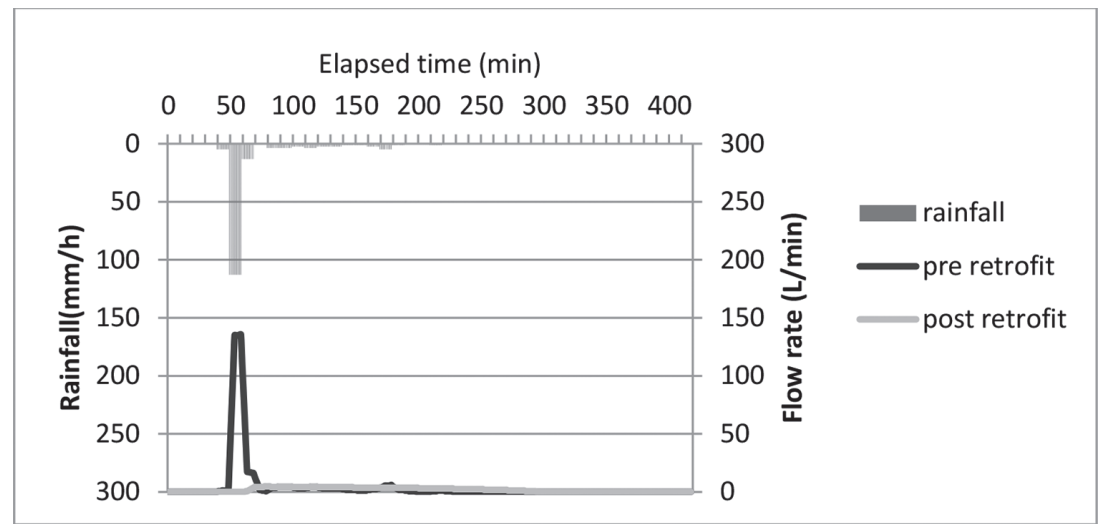

(h)

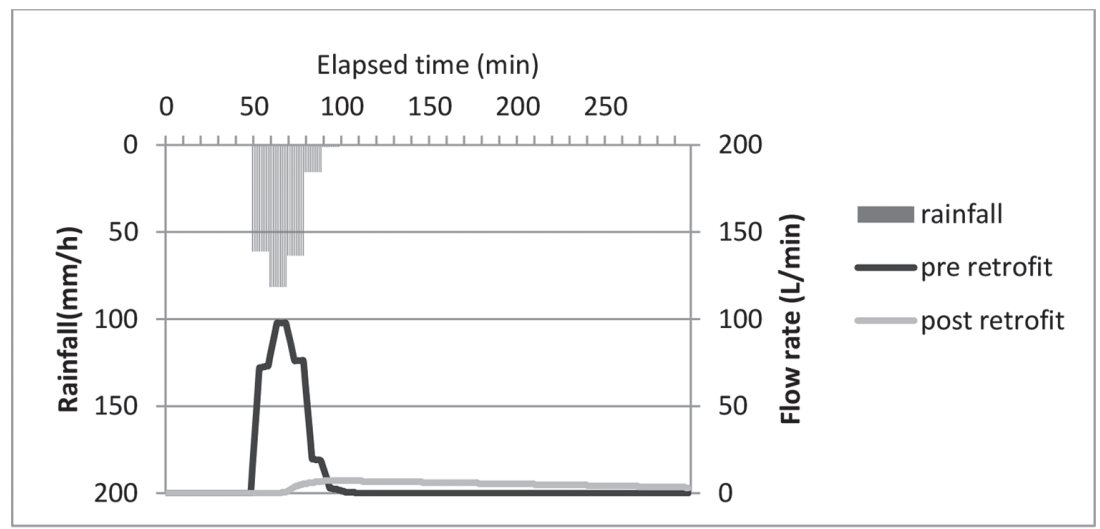

(i)

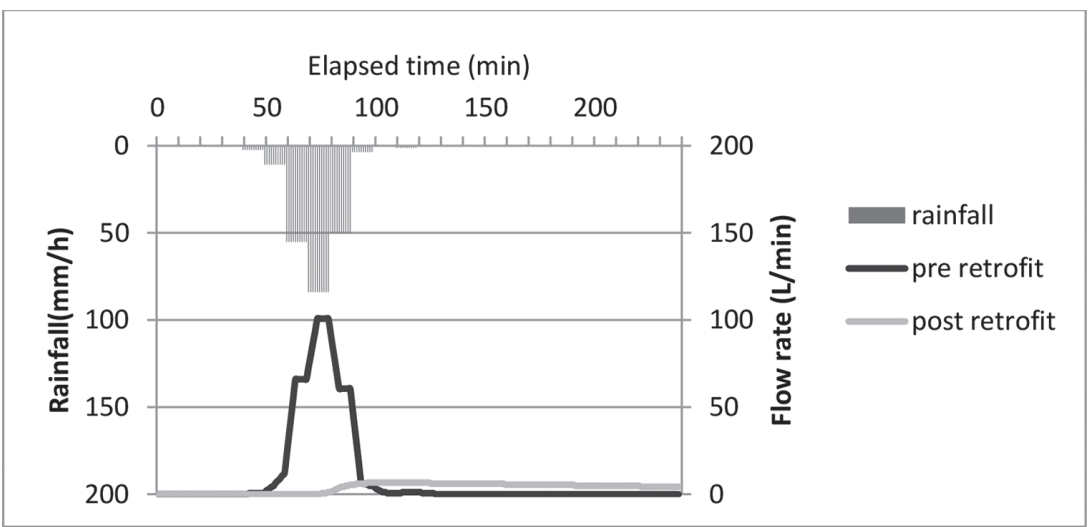

(j)

Figure 3: (Continued) 
Table 5: Volume pre and post retrofit for extreme single events.

\begin{tabular}{llll}
\hline Event Measured & $\begin{array}{l}\text { Volume pre } \\
\text { retrofit (liters) }\end{array}$ & $\begin{array}{l}\text { Volume post } \\
\text { retrofit (liters) }\end{array}$ & $\begin{array}{l}\text { Volume } \\
\text { reduction }\end{array}$ \\
\hline $06 / 07 / 2006$ & 3202 & 1530 & $52 \%$ \\
$04 / 07 / 2007$ & 382 & 0 & $100 \%$ \\
$12 / 07 / 2008$ & 1995 & 668 & $67 \%$ \\
$07 / 07 / 2009$ & 8816 & 7192 & $18 \%$ \\
$11 / 07 / 2010$ & 1750 & 623 & $64 \%$ \\
$27 / 05 / 2011$ & 2466 & 1167 & $53 \%$ \\
$09 / 06 / 2012$ & 2692 & 862 & $68 \%$ \\
$24 / 08 / 2013$ & 1905 & 733 & $62 \%$ \\
$24 / 06 / 2014$ & 2690 & 1222 & $55 \%$ \\
$25 / 07 / 2015$ & 2443 & 867 & $65 \%$ \\
\hline
\end{tabular}

Table 6: Volume pre and post retrofit for extreme single events at city level.

\begin{tabular}{llll}
\hline Event Measured & $\begin{array}{l}\text { Volume pre- } \\
\text { retrofit }\left(\mathrm{m}^{3}\right)\end{array}$ & $\begin{array}{l}\text { Volume post } \\
\text { retrofit }\left(\mathrm{m}^{3}\right)\end{array}$ & Reduction \\
\hline $06 / 07 / 2006$ & 4915 & 2349 & $52 \%$ \\
$04 / 07 / 2007$ & 586 & 0 & $100 \%$ \\
$12 / 07 / 2008$ & 3062 & 1025 & $67 \%$ \\
$07 / 07 / 2009$ & 13533 & 11040 & $18 \%$ \\
$11 / 07 / 2010$ & 2686 & 956 & $64 \%$ \\
$27 / 05 / 2011$ & 3785 & 1791 & $53 \%$ \\
$09 / 06 / 2012$ & 4132 & 1323 & $68 \%$ \\
$24 / 08 / 2013$ & 2924 & 1125 & $62 \%$ \\
$24 / 06 / 2014$ & 4129 & 1876 & $55 \%$ \\
$25 / 07 / 2015$ & 3750 & 1331 & $65 \%$ \\
Average & 4350 & 2282 & $60 \%$ \\
\hline
\end{tabular}

\subsection{Retrofit impact on city level}

Table 6 shows the effect in terms of runoff volume reduction at city level, using the infiltration-exfiltration system along both the inner and outer road street rings of Milano. With an average contribution of $4350 \mathrm{~m}^{3}$ of water volume on extreme single events the retrofit could reduce this volume on $60 \%$ with $2069 \mathrm{~m}^{3}$ of water being managed on its source. A broader impact could be achieved by using this system on more roads.

\section{CONCLUSION}

The presented preliminary study shows that the linear infiltration-exfiltration system has a significant effect on total runoff volume and peak flow reduction for extreme single events. The retrofit of the street gutters using this system would reduce on $60 \%$ the water volume 
directed to the sewers. Although the total water volume infiltrated by the system could be considered low when compare with the whole Milan basin this solution could be applied combined with other SUDs to achieve a sustainable and cost effect solution for the flood problem. The system would also have a positive impact on runoff water load removal which is solely a good reason for its application. With satisfactory preliminary results the effects of this type of street retrofitting will be further investigated, enhancing the modelling, for example considering the possibility of system pre-filling in the case of close-range rainfall events in a row, including load removal and applying the system on a higher area.

\section{ACKNOWLEDGEMENTS}

The authors acknowledge the contribution from Capes for funding this work through the scholarship number BEX 9224/13-0.

\section{REFERENCES}

[1] Becciu, G. \& Paoletti, A., Fondamenti di costruzioni idrauliche. Utet Scienze tecniche, 2010.

[2] Becciu, G., Ghia, M. \& Mambretti, S., A century of works on river Seveso: from unregulated development to basin reclamation. International Journal of Environmental Impacts, 1(4), pp. 461-472, 2018.

https://doi.org/10.2495/EI-V1-N4-461-472

[3] Lamera, C., Becciu, G., Rulli, M.C.\& Rosso, R., Green roofs effects on the urban water cycle components. Procedia Engineering, 70, pp. 988-997, 2014.

https://doi.org/10.1016/j.proeng.2014.02.110

[4] Marchioni, M.L. \& Becciu, G., Permeable pavement used on sustainable drainage systems (SUDs): a synthetic review of recent literature. WIT Press Urban Water II, p. 12, 2014.

[5] Sansalone, J.J. \& Teng, Z., Transient rainfall-runoff loadings to a partial exfiltration system: implications for urban water quantity and quality. Journal of Environmental Engineering, 131(8), pp. 1155-1167, 2005. https://doi.org/10.1061/(asce)0733-9372(2005)131:8(1155)

[6] Cipolla, S.S., Maglionico, M. \& Stojkov, I., A long-term hydrological modelling of an extensive green roof by means of SWMM. Ecological Engineering, 95, pp. 876-887, 2016. https://doi.org/10.1016/j.ecoleng.2016.07.009

[7] Jain, G.V., Agrawal, R., Bhanderi, R.J., Jayaprasad, P., Patel, J.N., Agnihotri, P.G. \& Samtani, B.M., Estimation of sub-catchment area parameters for Storm Water Management Model (SWMM) using geo-informatics. Geocarto International, 31(4), pp. 462-476, 2016. https://doi.org/10.1080/10106049.2015.1054443

[8] Krebs, G., Kokkonen, T., Valtanen, M., Koivusalo, H. \& Setälä, H., A high resolution application of a stormwater management model (SWMM) using genetic parameter optimization. Urban Water Journal, 10(6), pp. 394-410, 2013. https://doi.org/10.1080/1573062x.2012.739631

[9] Sahoo, S.N. \& Sreeja, P., A methodology for determining runoff based on imperviousness in an ungauged peri-urban catchment. Urban Water Journal, 11(1), pp. 42-54, 2014. https://doi.org/10.1080/1573062x.2013.765491 
[10] Sajjan, A.K., Gyasi-Agyei, Y. \& Sharma, R.H., Rainfall-runoff modelling of railway embankment steep slopes. Hydrological Sciences Journal, 58(5), pp. 1162-1176, 2013. https://doi.org/10.1080/02626667.2013.802323

[11] Skotnicki, M. \& Sowiński, M., The influence of depression storage on runoff from impervious surface of urban catchment. Urban Water Journal, 12(3), pp. 207-218, 2015. https://doi.org/10.1080/1573062x.2013.839717

[12] Rossman, L.A., Storm Water Management Model User's Manual, version 5.0. National Risk Management Research Laboratory, Office of Research and Development, US Environmental Protection Agency Cincinnati, 2010.

[13] Campisano, A., Catania, F.V. \& Modica, C., Evaluating the SWMM LID Editor rain barrel option for the estimation of retention potential of rainwater harvesting systems. Urban Water Journal, 14(8), pp. 876-881, 2017. https://doi.org/10.1080/1573062x.2016.1254259

[14] Sansalone, J., Liu, B. \& Ying, G., Volumetric filtration of rainfall runoff. II: Eventbased and interevent nutrient fate. Journal of Environmental Engineering, 136(12), pp. 1331-1340, 2010. https://doi.org/10.1061/(asce)ee.1943-7870.0000286

[15] Raimondi, A. \& Becciu, G., Probabilistic design of multi-use rainwater tanks. Procedia Engineering, 70, pp. 1391-1400, 2014. https://doi.org/10.1016/j.proeng.2014.02.154

[16] Becciu, G., Lewis, C., Mambretti, S. \& Sanfilippo, U., Design Rainfalls in a Climate Changing World. WIT Transactions on The Built Environment, Vol. 139, 2014.

[17] Raimondi, A. \& Becciu, G., On pre-filling probability of flood control detention facilities. Urban Water Journal, 12(4), pp. 344-351, 2015. https://doi.org/10.1080/1573062x.2014.901398

[18] Becciu, G. \& Raimondi, A., Factors affecting the pre-filling probability of water storage tanks. WIT Transactions on Ecology and the Environment, Vol. 164, pp. 473-484, 2012. 